\title{
X-Ray Microanalysis and Image Mapping of Elements from Eggshells of Freshly Laid Eggs of Green Sea Turtles Chelonia mydas
}

\author{
T. A. Ba-Omar ${ }^{*}$, I. Al-Amri ${ }^{* *}$, I.Y. Mahmoud", S. N. Al-Bahry ${ }^{*}$, A.Y. Al-Kindi ${ }^{*}$ and \\ J.L. Plude ${ }^{* * *}$ \\ *Department of Biology, College of Science, Sultan Qaboos University, P.O.Box 36 \\ Muscat 123, Sultanate of Oman. \\ ** Department of Pathology, EM Unit, College of Medicine, Sultan Qaboos \\ University, Sultanate of Oman. \\ ***Department of Chemistry, College of Letters and Science, University of \\ Wisconsin Oshkosh, WI 54901 USA
}

The eggs of the sea turtle are pliable with a leathery surface. Eggshells provide protection and maintain a favorable environment of fluids and air for the embryo. Few studies have been conducted on analysis of eggshells of the sea turtles [1]. This study, using samples collected from Ras Al-Hadd, Oman, is directed at the composition of eggshells shortly after oviposition.

Green turtle Chelonia mydas eggs were taken at oviposition for X-ray microanalysis and image. Untreated eggshells were analyzed for elemental composition and image mapping with an Oxford energy dispersive x-ray spectrometer (EDS) operating at $20 \mathrm{kV}$ and a working distance (WD) of $20 \mathrm{~mm}$. This involved qualitative, quantitative and area analysis. Qualitative analysis of characteristic X-rays (elements) distribution was displayed as a spectrum. SEM Quant (Oxford Instruments Ltd.) was used for quantitative analysis with ZAF internal standardardization (5 iterations), all elements and element composition expressed as weight percent. Representative sites were chosen for area analysis or image mapping of element distribution.

The eggshell consists of three components: an outer layer with loose and irregular shaped crystallites, an inner layer with compact crystallites and some fibers and an eggshell membrane with predominately fibers (Fig. 1).

X-Ray microanalysis and image mapping of freshly laid eggshells revealed different element compositions associated with these components.

The X-Ray spectrum of the fresh eggshells showed that the most abundant element was calcium (Fig. 2 a,b,c). Other major elements $(>0.3 \%)$ included the chalcogens carbon, oxygen, sulfur, and the environmentally significant heavy metals zinc and copper. Quantitative and area analysis of the shells three layers showed some variation in the element distribution with a significant change in calcium weight percent from outer to compacted inner layer. The presence of easily detected heavy metals will be investigated further as an external indicator of metal burdens of the green turtle.

Reference:

[1] G. Saho et al.. (1996). Acta Anat. 156:261-267. 


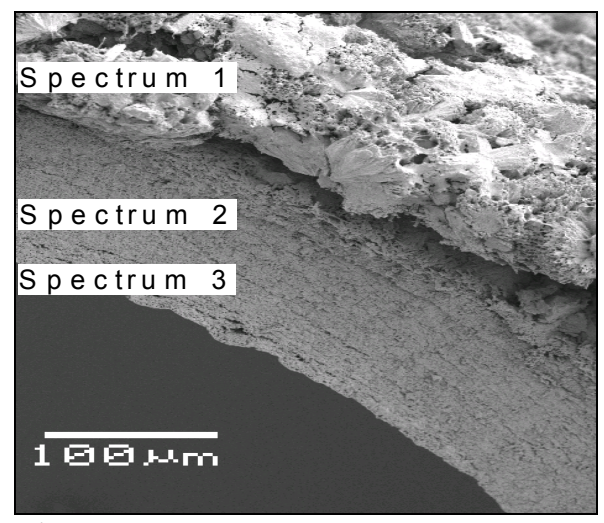

Fig 1.

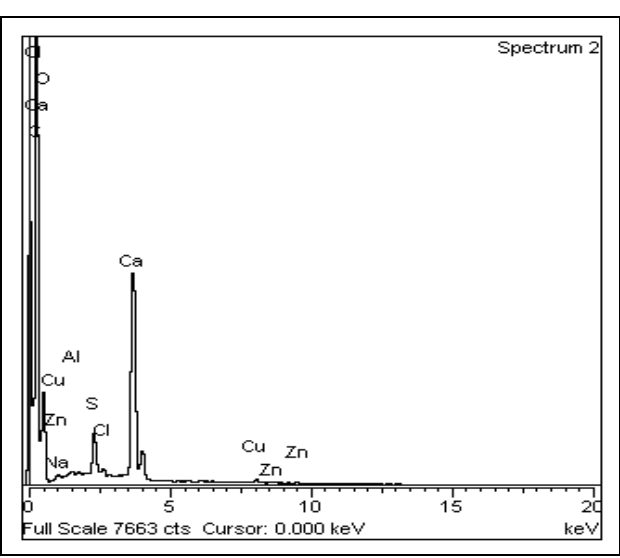

Fig 2. b

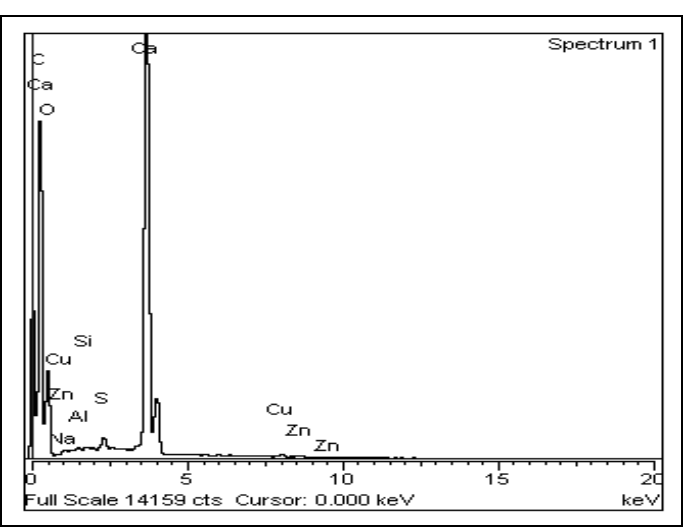

Fig 2. a

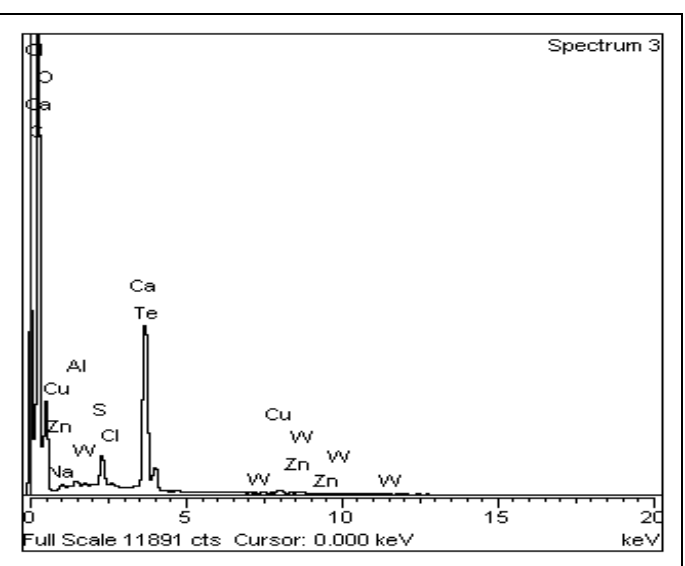

Fig 2. c

Fig 1. Eggshell showing; outer layer (Spectrum 1), inner layer (Spectrum 2) and eggshell membrane (Spectrum 3).

Fig 2. Spectra of eggshell layers. a. Outer layer (Spectrum 1), b. Inner layer (Spectrum 2) and eggshell membrane (Spectrum 3).

Table 1. Percentage weight of elements ( $\mathrm{SE} \pm$ ) in the three spectra based on 8 readings, $\mathrm{ND}=$ Non-detectable.

\begin{tabular}{|c|c|c|c|}
\hline Element & Spectrum 1 & Spectrum 2 & Spectrum 3 \\
\hline $\mathrm{C}$ & $31.35 \pm 0.26$ & $22.73 \pm 0.23$ & $33.30 \pm 0.27$ \\
\hline $\mathrm{O}$ & $22.26 \pm 0.35$ & $10.90 \pm 0.24$ & $15.97 \pm 0.29$ \\
\hline $\mathrm{Na}$ & $0.14 \pm 0.05$ & $0.08 \pm 0.03$ & $0.16 \pm 0.04$ \\
\hline $\mathrm{Al}$ & $0.09 \pm 0.02$ & $0.06 \pm 0.01$ & $0.12 \pm 0.02$ \\
\hline $\mathrm{S}$ & $0.34 \pm 0.02$ & $0.60 \pm 0.02$ & $0.67 \pm 0.03$ \\
\hline $\mathrm{Cl}$ & $\mathrm{ND}$ & $0.11 \pm 0.02$ & $0.10 \pm 0.02$ \\
\hline $\mathrm{Ca}$ & $17.31 \pm 0.09$ & $4.41 \pm 0.05$ & $5.43 \pm 0.06$ \\
\hline $\mathrm{Cu}$ & $0.49 \pm 0.07$ & $0.32 \pm 0.05$ & $0.50 \pm 0.06$ \\
\hline $\mathrm{Zn}$ & $0.28 \pm 0.08$ & $0.24 \pm 0.06$ & $0.30 \pm 0.08$ \\
\hline $\mathrm{W}$ & $\mathrm{ND}$ & $\mathrm{ND}$ & $0.15 \pm 0.04$ \\
\hline $\mathrm{Te}$ & $\mathrm{ND}$ & $\mathrm{ND}$ & $0.32 \pm 0.11$ \\
\hline $\mathrm{Si}$ & $0.07 \pm 0.02$ & $\mathrm{ND}$ & $\mathrm{ND}$ \\
\hline
\end{tabular}

